\title{
Article \\ Queering the Support for Trafficked Persons: LGBTQ Communities and Human Trafficking in the Heartland
}

\author{
Corinne Schwarz ${ }^{1, *}$ and Hannah E. Britton ${ }^{1,2}$ \\ ${ }^{1}$ Department of Women, Gender, and Sexuality Studies, University of Kansas, Lawrence, KS 66044, USA; \\ E-Mails: cschwarz@ku.edu (C.S.), britton@ku.edu (H.E.B.); Tel.: +1-785-864-2310 (C.S.) \\ ${ }^{2}$ Department of Political Science, University of Kansas, Lawrence, KS 66044, USA \\ * Corresponding author
}

Submitted: 27 August 2014 | In Revised Form: 8 December 2014 | Accepted: 10 December 2014 |

Published: 23 February 2015

\begin{abstract}
Human trafficking justice centers on the "Three Ps" model of prevention, protection, and prosecution. While protection and prosecution efforts have been moderately successful, prevention remains elusive, as "upstream" structural factorsclass, gender, and sexuality inequalities - remain difficult to target. Individuals who are affected by these factors are not fully served within linear service frameworks. Based on a 12-month study in Kansas City, we find that service providers recognize the limitations of a "one-size-fits all" approach. Using a public health model, our research team conducted a public health surveillance, explored risk and protective factors, and facilitated organizational self-assessments of services. Our findings support a prevention approach that supports a survivor-centered model, which creates new, nonlinear or queered avenues of agency and community for trafficking survivors. This model allows survivors to make use of services in moments of vulnerability and opt out of others in moments of resilience. Given the systematic cuts in funding that have affected service providers, this research contends that prevention is cheaper, more effective, and more ethical than relying on prosecutions to curb trafficking. Developing a model that fosters survivor empowerment is a key step toward individual justice and survivor resilience for vulnerable and marginalized populations.
\end{abstract}

\section{Keywords}

agency; human trafficking; LGBTQ; prevention; public health

\section{Issue}

This article is part of the special issue "Perspectives on Human Trafficking and Modern Forms of Slavery", edited by Siddharth Kara (Harvard Kennedy School of Government, USA).

(C) 2015 by the authors; licensee Cogitatio (Lisbon, Portugal). This article is licensed under a Creative Commons Attribution 4.0 International License (CC BY).

\section{Introduction}

Understanding the size, scope, and causes of human trafficking ${ }^{1}$ remains a persistent challenge (Farrell et al.,

\footnotetext{
${ }^{1}$ As this project is based in the U. S., we used the Trafficking Victims Protection Act as our standard definition for trafficking, which we hope is expanded through this article to include a range of survivors and also a range of vulnerability and resilience that fall outside legal frameworks. We are also concerned with the range of trafficking: sex trafficking, child
}

2009; Farrell, McDevitt, \& Fahy, 2010; Gozdziak \& Collett, 2005; Laczko \& Gramegna, 2003; Tyldum \& Brunovskis, 2005; United States Department of Justice, 2006; Weit-

sex trafficking, labor trafficking, forced labor, bonded labor or debt bondage, involuntary domestic servitude, forced child labor, and instances when smuggled persons may become exploited and trafficked. While it is outside the TVPA, we also are looking for instances of organ trafficking. At of the date of writing, no cases of organ trafficking have been presented in the project. 
zer, 2005). But trafficking is a hidden, illicit trade, and those who are currently trafficked may be unable to seek assistance because they may not identify as trafficked or because they are concerned about deportation, violence, retribution, or abuse (Icduygu \& Toktas, 2002; Primrose, 2011; Zhang, 2012). Scholarship and advocacy in this area tends to concentrate on the protection of survivors ${ }^{2}$ and the prosecution of perpetrators, but it often overlooks how to prevent the crime and exploitation (Annitto, 2011; Bales \& Trodd, 2008; Brennan, 2005; Clawson \& Dutch, 2008; Long, 2012; Primrose, 2011).

This project uses a different approach, taking the public health approach of looking "upstream" for the macro-level inequalities that perpetuate exploitation and trafficking "downstream" on the micro-level. We expand the focus to consider multiple vulnerable populations and systematically explore the individual and structural risk factors. We are interested in understanding the cycles of vulnerability individuals face as well as the ways services could be adapted to fit the unpredictable, non-linear needs of survivors. This project finds that in order to support someone exiting trafficking, it is crucial to challenge the latent notions of an "ideal" or "model" victim. Though the iconic victim is traditionally coded as young, white women trafficked domestically or women of color trafficked internationally, the population of survivors is much more diverse (Srikantiah, 2007). In particular, the ostensibly straight young women who must be rescued by (male) law enforcement through the prosecution process serves as a foil to the numerous queer ${ }^{3}$ bodies who are vulnerable,

\footnotetext{
2 In this article, we are intentional about the use of the terms victim and survivor, as we are calling for a change in that language. We use the term "victim" when referring specifically to the idea of an "ideal victim" or in cases where our interview participants used the term themselves. We use the term "survivor" or "trafficked persons" in all other cases to reflect our belief that survivors have agency and often operate outside of the victim framework that is applied to them. Other scholars have made a different distinction, referring to someone currently trafficked as a victim and those who have exited as survivors. While we are supportive of that distinction, in this article we use the language of survivor or trafficked person in order to retain the idea of agency and selfdefinition we have seen within the survivor community. We are also aware of the vertical relationship implied by the terms survivor and provider. However, this relationship is not so hierarchically fixed, as the agencies we met with are working in partnership with trafficked persons, and several organizations are survivor-led, again disrupting the idea that there is some finite distinction between survivors and providers.

${ }^{3}$ In the context of this paper, we will be specifically focusing on members of the LGBTQ community. We recognize that queer can describe a variety of non-normative bodies and that multiple, intertwined identities-race, citizenship, ability-can complicate sexual orientation and gender identity
}

exploited, and trafficked and require culturally competent resources.

Our research indicates that in order for trafficking prevention models to be successful, agencies and policy-makers should destabilize the typical service model that assumes a linear progression from risk-taking behavior or vulnerability toward a position of security and stability. Instead, social service providers and antitrafficking advocates utilize a "client-first" approach, which recognizes that survivors move in and out of risk and security and that there is no single package of mechanisms for each survivor. What most frustrates and troubles policy makers and advocates is that every trafficking case is different (Brennan, 2005). Yet, what this teaches us is that there is no single model of risk or resilience for those exiting trafficking. An adaptable "survivor-first" model allows for survivors to opt in and out of services and resources as they need during times of vulnerability, while allowing them to build resilience skills during times of security and self-sufficiency.

This flexible, survivor-centered approach, focused on individual recovery and protection, needs to be combined with larger, structural investments into the framework of trafficking prevention. Our research finds that you cannot separate protection from prevention, given the cyclical nature of vulnerability among populations. Countries need ongoing, regular support for education, jobs training, housing and health care, etc. - the basic fundamentals for a strong, trafficking-resistant society. What is most troubling is that the very things needed to create trafficking-resistant societies are increasingly under threat in the "current and persistent economic crisis" and the "impending implosion of the welfare state" (Hedetoft, 2013, p. 2). Because of the international nature of trafficking economics, the pressures on survivors and their advocates are also increasing due to the growing anti-immigration policies and rhetoric and because of migration pressures from war, environmental changes, and economic marginalization. Prevention is more effective and less costly than assisting survivors after they have been trafficked or using prosecution-approaches to deter traffickers. Prevention also is arguably more ethical than waiting until after the exploitation has occurred to react.

The defunding of social services and the welfare state continues to distance the members of society most vulnerable to trafficking from the institutions and structure they most need. In particular, the bodies and lives that are the least legible then become even more

even further. However, we will be utilizing two terms throughout this paper: LGBTQ to name the larger community operating in Kansas City and trans* to specifically call attention to transgender men, transgender women, and all other self-identifying members of the transgender community, as trans* individuals were specifically mentioned as a vulnerable population throughout our interview process. 
separated from the democracy that was intended to include them. Halberstam (2005), in discussing the work of James C. Scott, argues that:

Democracy is now riddled with pockets of intense and naked oppression that both shore up the attraction of democratic rule and fortify the myth of its totality. For those subjects-nonmetropolitan queers, prisoners, homeless people, undocumented laborers - who find themselves quite literally placed beyond the reach of federal protection, legal rights, or state subsidy, democracy is simply the name of their exclusion. (pp. 34-35)

As the anti-trafficking movement becomes more and more an anti-trafficking industry, it has also become linked to the criminal and carceral state ${ }^{4}$. While many hoped to find ways to expand spaces within democracy to protect these non-normative lives, the trafficking laws and policies are often operationalized as incarceration, deportation, or detention-rather than education, training, health care, and housing support that might prevent vulnerability.

Thus, the findings in this study present a case for both collective, structural responses to vulnerability combined with individual rehabilitation and recovery plans. Solely focusing on survivor-centered approaches to trafficking will not address the societal-level factors that push and pull persons into exploitation and vulnerability, such as war, gender inequality, discrimination, and social inequity (Britton \& Dean, 2014; Goodey, 2008). Similarly, focusing only on nationallevel responses has led internationally to a focus on anti-immigration policies, crime, law enforcement, and prosecution at the cost of protecting survivors and advancing human rights (Goodey, 2008; Kaneti, 2011; Lindstrom, 2006; Smith, 2011). Countries need a comprehensive plan for making their communities trafficking-resistant by decreasing the systemic vulnerability of populations. Simultaneously, they need service providers who are nimble enough to ensure that protection services offered during survivor crisis are flexible and can adapt to cyclical, unexpected survivor needs. Focusing on prevention, rather than prosecution, is both more effective and less costly than prosecution approaches. A prevention approach also addresses the ethical costs of focusing only on prosecutions-which are inherently reactive and happen after exploitation has occurred.

\section{Public Health Approaches to Trafficking Research}

Building on the studies focusing on prosecution and protection of survivors (Annitto, 2011; Bales \& Trodd,

\footnotetext{
${ }^{4}$ Special thanks to the anonymous reviewers for this observa-
} tion.
2008; Brennan, 2005; Clawson \& Dutch, 2008; Farrell et al., 2009, 2012; Long, 2012; Primrose, 2011), our work takes a new direction and implements what Jonathan Todres $(2011,2012)$ has called a public health model to research human trafficking. In this study, the research team employed a public health prevention approach advocated by scholars (National Research Council of the National Academies \& Institute of Medicine, 2013; Todres, 2011, 2012) to identify the risk and protective factors that may contribute to vulnerability and exploitation. This is not an attempt to medicalize trafficking or the health risks of survivors. Instead, the research team utilized the four-level ecological model of violence prevention (Center for Disease Control, 2013) that includes individual, relationship, community, and social factors in order to understand the interconnected patterns and forces that contribute to vulnerability.

A public health framework allows anti-trafficking advocates to move outside of the prosecution-centered models of intervention. As Zimmerman, Hossain and Watts (2011) explain, utilizing the judicial system "is a useful framework for law enforcement approaches, [but] it neglects the fundamental migratory nature of trafficking and minimises the health sector role" (p. 328). Early interventions to combat the "upstream" factors of trafficking can and should occur in health sectors-especially since up to $50 \%$ of survivors seek medical care during their exploitation (Konstantopoulous et al., 2013) - but require needed research before implementation. A public health approach that uses evidence-based research to promote trafficking prevention at micro- and macro-levels is crucial to balancing the "three Ps" in anti-trafficking efforts (Todres, 2011).

First, the research team used an institutional approach, collaborating with service providers (e.g., social welfare officers, homeless shelters, and schools) to gain a broad perspective of trafficking and vulnerability in the research area-the Kansas City metro areawith the understanding of the complexity and hidden nature of trafficking. Second, we conducted interviews with key service providers to map and delineate the wide range of survivors, their narratives, their histories and backgrounds, and their ongoing and unmet needs for survival and to exit of trafficking.

\section{Using New Theoretical Frameworks to Address Vulnerability}

While the range and substance of the interviews are expansive, for this article we are particularly interested in examining specific subsets of our sample that deal with LGBTQ populations, that describe non-normative survivors, or that talk in direct terms about survivorcentered and/or non-linear approaches to survivor services. Their experiences, their understanding of their own needs and strengths, and their articulation of a continuum of life experiences prompted us, first, to 
look outside typical policy or program frameworks frequently used in trafficking work and, second, to look for more fluid understandings of identity, survival, and resilience. Though they seem initially very different, homeless youth, undocumented migrants, and trans* individuals are all targeted by traffickers who pray on their housing insecurity, economic insecurity, or personal vulnerability. In a prosecution-focused model of anti-trafficking work, these groups remain the most vulnerable through their relationship to the carceral state-all of these groups are vulnerable inside and outside of the system.

As often cited in the literature on homeless youth and transitional housing, LGBTQ populations are particularly vulnerable to exploitation, marginalization, and isolation. Housing insecurity is a significant issue, as LGBTQ youth are disproportionately represented in homeless youth populations (Gordon \& Hunter, 2013). As Gordon and Hunter (2013) find, "because of their families' reactions to their sexual orientation and the exploitation they sometimes experience in their communities", (p. 37) queer homeless youth are often left without the safety nets afforded to many of their equally-vulnerable peers: homeless shelters might not open their doors to gender non-conforming youth, or foster care placements might not be accepting of openIy LGBTQ youth in their homes. Without these safety nets, LGBTQ youth must negotiate their survival independently within a limited set of options, often turning to exploitative and dangerous practices. For example, in their study of LGBT runaway-homeless youth in New York City, Ferguson-Colvin and Maccio (2012) found that this population was subjected more frequently to sexual victimization than heterosexual runawayhomeless youth and more likely to engage in prostitution or survival sex for food, clothing, or shelter (p. 9).

Our findings about the particular vulnerability of LGBTQ persons to trafficking led us to think about how non-normative bodies and identities can be instructive in reshaping our understanding of prevention and protection, regardless of sexuality identity. The LGBTQ community in this project taught us that their particular sites of vulnerability led to new avenues of resilience. Those bodies and lives that are outside the norm are particularly vulnerable to discrimination, exclusion, and violence-and yet they are also highly resilient and able to create new ways of developing survival skills and new ways of conceptualizing services.

Queer theory, although rooted in the early movement politics of the LGBTQ community, has evolved to become synonymous with bodies, identities, politics, and subjectivities that occur outside the norm or that deviate from a "normal" vision of what a life should look like. Theorist Halberstam (2005) sees queer time and space in opposition to normative temporal and spatial tropes, which rely upon "respectability, and notions of the normal...upheld by a middle-class logic of reproductive temporality" (p. 4). Time and place are defined by their proximity to heteronormative ${ }^{5}$ life stages or events-graduation from educational institutions, marriage, childbirth, the purchase of homes or cars. While these are not inherently oppressive or negative, taken together, these acts represent an ordered, linear life of reproduction and consumption with little room for deviation or agency. In contrast to this system, Halberstam (2005) sees queer time and place as providing different ways of being.

With its emphasis on blurring binaries and disrupting normative boundaries, queer theory can radically disrupt how we understand and use the institutions that structure our lives. The normative conceptions of linearity-a logical, forward movement from an origin story to an appropriate endpoint-that undergird these institutions gain new, subversive potential. While traditional conceptions of progress require a linear path from failure to success, from risk to resilience, the non-normative approach advocated by queer theory introduces gaps and loops as well as new definitions of progress.

It is important to note that the social service providers in the Kansas City metro are not exclusively providing queered services. Across the area, survivors could access legal aid for specific cases, GED programs, individual or group therapy, and housing and jobs assistance, all with normative "successful" outcomes. The difference is that many of these organizations and providers offer linear, traditional programs that are informed by their survivor-centered approaches. A domestic violence shelter offered transitional housing services for their clients, giving women case management and therapeutic services alongside apartment searches and financial assistance for rent. The ultimate goal of this program was to see women living independently in their own homes or apartments, an end goal that would fit with more normative approaches. However, they partnered this program with traumainformed care. The shelter director explained:

Every single staff person...has completed 20 hours of trauma-informed care training to be able to understand what has happened to the people that, you know, precipitate the types of behavior that make them so vulnerable to domestic violence, but would also be the same factors that would make them vulnerable to trafficking (Interview by author, November 14, 2013).

Within this programming, staffers explored the larger factors that would inform the individual survivor's experience, factors that create a cycle of violence that women might reenter even after completing rehabilita-

\footnotetext{
${ }^{5}$ Heteronormative means to assume heterosexuality as the default, privileged, normative position for individuals in society.
} 
tive services. By keeping tabs on the structural factors of domestic violence and interpersonal violence, this shelter acknowledged that their clients might need multiple attempts at "success" before being able to fully escape.

The new ideas of time, progress, and survival Halberstam presents give us important alternative ways of understanding the lives and experiences of trafficked persons-people who often have major interruptions or threats in their educational path, in their quest for family and security, and in their physical safety. These survivors may not respond to services that demandeither overtly or implicitly-that they follow a linear path toward success.

If both queer time/place and risk and resilience operate on a continuum, then the potential for subjectdriven agency increases, disrupting the idea of one structured life path. Not all survivors can fit into a linear model of prevention and protection, especially those that live outside social norms either by choice or through duress and the fight for survival. Yet these practices are presented as the only options for social legibility: complete treatment, return home, live a productive life, and never return to these cycles of violence or exploitation again. Within this linear model, we cannot make sense of survivors who are addicts refusing to go through rehabilitation, survivors who are sex workers continuing to work as prostitutes, or survivors who are homeless returning to the streets-those survivors who exercise their agency in ways that contradict heteronormative success. Halberstam's (2005) idea of non-normative time and place acknowledges that, "all kinds of people, especially in postmodernity, will and do opt to live outside of reproductive and familial time as well as on the edges of logics of labor and reproduction" (p. 10). The choice to operate as a subject outside of social norms for whatever reason-"deliberately, accidentally, or of necessity"-does not lead to erasure (Halberstam, 2005, p. 10). Rather, non-normative subjects-in our case youth, trans* individuals, undocumented persons-coexist on a continuum that recognizes the agency present in their disruption of their lives, their physical security, and their opportunities.

While the social service sector is a very specific institution, it is imprinted with the same normative concepts of time and place that structure how we move about the world. Halberstam (2005) writes:

In Western cultures, we chart the emergence of the adult from the dangerous and unruly period of adolescence as a desired process of maturation; and we create longevity as the most desirable future. We applaud the pursuit of long life (under any circumstances) and pathologize modes of living that show little or no concern for longevity. (p. 152)

Traditional social services follow this model, as survivors (ideally) move from a position of deviance and risk-for example, addiction, homelessness, or financial instability-to a position of stability and success, usually meaning a position of heteronormative, middle-class production and reproduction. The "successful" survivor is not dependent upon social services to the same degree, moving to a position of self-reliance and autonomy.

Depending upon the sector, social service providers envision their survivors as gainfully employed, reunited with functioning families, sheltered in a home, and removed from addictive behaviors. While this is certainly not an inappropriate goal-we do not wish to criticize social service providers seeking an improved material existence for their vulnerable or exploited survivors -it limits the definition of "successful" survivors to those who align closest to a linear concept of progress. Survivors who do not normatively shift from instability to stability are rendered illegible within its framework because they do not fit the model of the "ideal victim" (Britton \& Dean, 2014; Hoyle, Bosworth, \& Dempsey, 2011; Lobasz, 2009; Munro, 2008; O'Brien, 2012; Oxman-Martinez et al., 2005): for example, those who repeatedly return to the service organization or those who refuse to modify certain risky behaviors and are inappropriately deemed culpable in their own exploitation.

Since Halberstam's continuum links queer subjects through their agency-not their shared membership in a particular category-those inhabiting this space might not resemble each other in traditional ways of conceptualizing identity politics (i.e., by their race, class, gender, orientation, or ability). LGBTQ youth move in and out of social services next to undocumented laborers, domestic violence survivors, addicts, and homeless persons. Arguably, this collection of bodies is unintelligible, as their identification as vulnerable, exploited, or trafficked persons is not immediately recognizable-as many of the service providers we encountered explained, there is no "typical" survivor you can point out in a crowd. However, feminist theorists offer unique frameworks to create community amongst the disparate populations along this continuum, to bring othered persons into conversation with each other.

Ahmed's (2000) concept of the strange encounter offers a first approach to forging community by producing 'the figure of the 'stranger'...not as that which we fail to recognize, but as that which we have already recognized as a 'stranger'" (p. 3). All of the aforementioned groups can be deemed "strange" through their participation in survivor-centered services. We recognize them as unlike us-as non-normative-in their non-linear participation in services that seek to make them not "strange" through linear rehabilitation. Since Ahmed (2000) "examine[s] differentiation as something that happens at the level of the encounter rather than 'in' the body of an other" (p. 154), her theoretical framework is useful for reconceptualizing otherness as practices, not just bodily markers. Difference or other- 
ness is not inherent within subjects; it can be linked to the way these subjects negotiate the world just as it can be linked to how their bodies are seen by the world. For example, youth who are trying to exit sex trafficking may feel it necessary to continue to be trafficked while they are getting the funds and resources to secure housing or a safe place to live. Because of inadequate housing options, they may feel it necessary to gather enough resources to survive before they seek more sustainable assistance.

Feminist theory asks us to move beyond boundaries of race, class, and gender identities to think about where our identities intersect and come into conversation or coalition (Ahmed, 2000; Anzaldua, 1987; Crenshaw, 1989; Weir, 2008). If we use a feminist lens to understand new ways of working with lives that fall outside of the norm, we can start to shift "from a static to relational model" where we share "identification with others, identification with values and ideals, identification ourselves as individuals and as collectives" (Weir, 2008, p. 111). As survivors shift how they view their lives and experiences, as it is their agency to do, they can see themselves as participants and agents in their rehabilitation and survival.

\section{Explanation of Study Site}

This study examines trafficking in Kansas City, Missouri and Kansas City, Kansas, a major metropolitan city in the Midwest that is divided by a state line and surrounded immediately by rural areas. Leaders, advocates, and government officials in Kansas City are increasingly aware of the high levels of human trafficking-both labor and sex trafficking-in the region. ${ }^{6}$ Situated in the heartland of the U.S., Kansas City is on the crossroads of I-70 and I-35, major domestic traffic ways that bisect the country, with emblematic migration patterns for the domestic and international labor forces. Kansas City is often overlooked in US trafficking research, which focuses on the US coasts, border states, and larger major urban centers. Yet the patterns seen in Kansas City may be particularly instructive for anti-trafficking programs and policies in the heartland of the U.S.

Following the public health approach to preventing

\footnotetext{
6 Though quantitative data is notoriously difficult to attain, we are using proxy measures here. For example, we interviewed a lawyer who saw 170 victims during her tenure as a prosecutor. One lawyer estimates that the Western Missouri region moved from having no human trafficking prosecutions in 2003 to have the most prosecutions nationally by 2012 . According to the Polaris Project, their human trafficking hotline received 371 phone calls from Missouri, ranking it as $19^{\text {th }}$ out of all states, and 303 phone calls from Kansas, ranking it as $23^{\text {rd }}$ out of all states in 2013 . These numbers will continue to climb as the recognition and awareness of trafficking in the region is finally gaining attention.
}

trafficking outlined by Todres (2011), the research team first conducted an organizational scan of organizations and service providers working with vulnerable populations including women's shelters, homeless shelters, LGBTQ youth organizations, faith-based organizations, migrant labor organizations, schools, Englishlanguage learner classes, members of the local government, law enforcement, and county-level officials such as sheriffs, public defenders, members of the judiciary, foster care services, social service providers, and medical facilities that may encounter vulnerable persons. Additional organizations were added based on a snowball identification technique, based on the chain of referrals from our initial contacts. The research team identified 70 such organizations in the Kansas City metro area.

Second, the research team conducted selected interviews with these agencies. This article represents what we consider to be Phase One of our research project-developing the research model and interviewing key service providers. Our next phases will focus on expanding this research to rural areas in the Midwest, will include interviewing trafficked persons, and will include a longitudinal component in which we interview these organizations over several years. While the interviews for this project are ongoing, at the time of this writing the team conducted 36 interviews with service providers, ranging from thirty minutes to two hours in length. The research team used semi-structured interviews based on a consistent interview guide that was developed by an interdisciplinary team of faculty and graduate students. Interviewers were allowed to ask follow up questions beyond the interview guide's four sectors-general organizational questions, traffickingspecific questions, sector-specific questions, and public heath outcome questions-depending on the nature of the organization or the types of information the interview was yielding. ${ }^{7}$

Part of the ethical framework that guided this research is that we are interested in working with organizations and populations that are vulnerable to a range of abuse, vulnerability, violence, and exploitation-not just trafficking. While it would be empirically expeditious to track trafficked persons through their relationships across service providers and over time, this presents several ethical challenges of privacy and confidentiality. We placed these ethical considerations at the heart of our research design and thus interviewed a range of organizations that deal with vulnerable populations, including but not limited to trafficking vulnerability.

\footnotetext{
7 All interviews were conducted in English and were transcribed by members of the research team. For this article, transcripts were analyzed using Computer-Assisted Qualitative Data Analysis Software (CAQDAS), specifically Atlas.ti 7.1.6. In this analysis, we were interested in identifying and understanding news ways of approaching trafficking, service provision, and survivor needs.
} 


\section{Findings}

In the Kansas City metro area organizations we interviewed, we discovered that service providers see vulnerability, exploitation, and trafficking on the microand macro-levels. Change must occur at both the individual and structural level, as systems of inequality are not eradicated through one survivor's ability to leave and thrive. While the organizations we interviewed provided specific examples of how survivor-centered approaches work in practice, they also consistently mentioned the larger social norms that lead to this devaluation of certain bodies: rape culture, homophobia and transphobia, and "bootstrap" mentalities. The individual denigration of certain non-normative identities and the structural defunding of welfare state programs combine to leave certain survivors without necessary preventive or rehabilitative programs. Service providers were adamant that their survivor-centered approaches can and do work, but that we need massive social shifts to combat the continual cycles of violence and poverty that make so many people vulnerable in the first place. In the following section, we first discuss the micro-level approach to assisting survivors and then outline some of the macro-level policy adjustments that need to be made at the structural societal level.

\subsection{Reconceiving the Fluidity and Flexibility of Services}

The Kansas City metro area organizations interviewed for the ASHTI (Anti-Slavery and Human Trafficking Initiative) project provide a queerer approach to survivor services, one that transforms the social services sector from an institution reliant upon a linear approach to one that honors survivor agency on a less-direct path. Though these organizations do not name queer theories in describing their survivor-centered approaches, they certainly fit into Halberstam's flexible continuum: they provide a range of services that survivors can choose to accept or reject for whatever reason. A service provider from a sexual violence advocacy organization states:

I mean we are just there to provide the options to people. Sometimes they make decisions we recommend, and sometimes they don't, but that is okay, because that is what we are there for. We are there to help them make an empowered and informed decision (Interview by author, November 5, 2013).

A case manager from a state-level sexual violence advocacy organization echoes this, saying "It's up to the survivor to decide if they want to work with us or not, but they do get referred to us, and we do follow up with them. Then they make the decision about whether they want to work with us" (Interview by author, Oc- tober 21, 2013). If survivors do not want to join individual or group therapy, enter the legal system, or completely disengage from their current situation, they simply do not have to and, more importantly, can return to these services later.

This model requires service providers to redefine progress or success on an individual level-one survivor's success might be simply hearing the options for making an empowered and informed decision while another's might be following through with this information. Survivors who seek services that might not fully diminish these risks have not failed; rather, they have exercised their agency to regain some kind of control over aspects of their lives that once seemed uncontrollable. As the service provider from a sexual violence advocacy organization explains:

Sometimes that means we make decisions that we wouldn't think are the best for them, and we can see that being, you know, being an issue with human trafficking situations where, they might be like, "Well, this is what I am going to do", and we may be looking around like, "Oh no, don't do that", but that is not up to us. It is up to them. And that I mean, that comes about in all kinds of ways. I mean, it's not up to us to say, "Oh you should press charges", or "You should do this or you should go seek counseling". I mean we are just there to provide the options to people (Interview by author, November 5, 2013).

The staffers are not experts dispensing a regimented program of rehabilitation; the lived experiences of the survivors propel the programs. A "good" survivor might go through all legal channels and all programs offered, but this is a very large burden upon an individual that does not acknowledge the real issues of retraumatization or exhaustion that accompany these processes. A survivor-centered approach queers this narrative, disrupting how individuals navigate the sometimesoverwhelming variety of services they can access upon entering the social service sector.

\subsection{Redefining the Ideal Victim}

These social service providers also actively work toward reducing the stigmas surrounding survivors of trafficking. Though Kansas City is increasingly recognized as a hub for human trafficking, it remains an issue many local residents understand only through very stereotypical contexts. Survivors of trafficking are called into being as the Stranger in ways that do not reflect their lived experiences. The general public, and oftentimes policymakers, want to craft trafficking survivors into the ideal victim-someone who has been abducted, brought from a foreign country, devoid of agency, intelligence, or social legibility. Otherwise, they 
are constructed as complicit in their exploitation and, consequently, undeserving of assistance. A service provider from a domestic violence shelter sees connections with the limited perceptions of domestic violence survivors and trafficking survivors: "They must have done something; how could they be so..., why didn't they just deal with it, especially in sex trafficking. 'Well, if they hadn't put themselves in that position'" (Interview by author, November 14, 2013). In working against the stigmas, social service providers seek to reduce this hierarchical distance between trafficking survivors and others in the community.

In our interviews, service providers see differences in the ways their survivors express their own agency and vulnerability based on a range of factors, including age, gender, sexual orientation, or rural or urban status. A service provider in the foster care system addressed communication more typical of rural survivors:

A lot of the language, you know, pertains more to urban teens and a lot of the relationship kinds of things...I think things look a little bit different, you know, in Emporia, Kansas, than they do in Brooklyn, New York, so, you know, not universally, but I think in a lot of ways.... What I've seen is a lot more casual than that and a lot more matter of fact. It's more of like a...you know, "Yeah, I, my boyfriend, you know, asked me to sleep with his friend and then, you know, we stayed at these people's houses, and we were doing these drugs, and well, yeah, those other guys came over".... It's presented more as a lifestyle kind of thing. And a choice. Definitely a choice. These girls don't come in and say, "I'm a victim". They come in and say, "Yeah, what's the problem? I like sex, and I wanted to do it and like...what's the big deal? It's fine" (Interview by author, May 6, 2014).

While this quote necessarily reflects the experiences of only one service provider, it suggests existing research has limited applicability for a range of survivors that fall outside the aforementioned "ideal" model of trafficking victims (Britton \& Dean, 2014; Hoyle et al., 2011; Lobasz, 2009; Munro, 2008; O'Brien, 2012; OxmanMartinez et al., 2005) - in this case rural youth. Just as trafficking survivors cannot be reduced to one race, gender, or orientation, they cannot be reduced to one geographic specificity (i.e., urban), and anti-trafficking prevention must recognize the important differences in the regional backgrounds, history, and experiences of trafficked persons in order to be effective.

\subsection{Redistributing Power Horizontally}

Many of the organizations emphasized a more horizontal distribution of power between survivors and service providers. Though the social service providers are arguably in a position of authority over the survivors, they resist the patterns of domination that can manifest in these relationships, instead using a more affective framework. Weir (2008) writes, "[T]o identify with another is to love her; to 'welcome her world', to value her" (p. 123). An anti-trafficking non-profit emphasized the importance of valuing survivors. This service provider-herself a survivor of trafficking-gave her direct cell phone number to her survivors and visited them at their homes, a degree of intimacy divorced from many organizations' approaches. She also emphasized the importance of not judging their situations, positioning herself as an understanding friend or peer rather than a director of a non-profit organization. Instead of a more clinical, distanced relationship, one that requires the power of the social service authority to guide the survivor along a linear path, this kind of identificationwith constructs community rather than hierarchy.

A coordinator for an ESL/GED program noted the importance of a teacher/student and student/student relationship within her program, as many of the students came from particularly vulnerable backgrounds. As their program does not require proof of citizenship, some enrolled students were undocumented, brought to the United States under suspicious circumstances: marriages that resembled "mail-order bride" set-ups, job programs with huge fees and fines for enrollment. At a minimum, their lack of English language training prohibited them from finding a larger community for support. Teachers offered advice on how to navigate various issues within their workplaces and family lives, often to extremes beyond their qualifications. However, she explained:

The biggest thing is the relationship they build, not only with their teachers but also with the cohort of the students as they move through the program together. They just really support each other. When they have successes, everybody celebrates together. A lot of that is just that they bring food and they eat at break together. They become sort of a family. It's really neat. I think that is sort of important. I also see like an age thing, where you'll sometimes see the older women mentoring along the younger women and men too (Interview by author, November 20, 2013).

For survivors made vulnerable through a lack of these supportive systems - LGBTQ youth whose families have rejected them, survivors of domestic violence whose partners isolated them from their communities, undocumented persons whose legal status requires secrecy and distance-a more egalitarian, communal structure within these social service organizations can be hugely important. Though teachers might have their students' best interests in mind, their primary role is still to teach English language and educational preparatory skills-they are not licensed social workers, law- 
yers, or doctors, and thus cannot deal with the multiple issues many of their students face. However, they can create and foster a familial atmosphere among students, expanding the resources students can turn to in times of emotional trauma.

\subsection{Survivor-Centered Approaches for LGBTQ Youth}

The few Kansas City-area organizations that explicitly work with LGBTQ persons-trafficked or otherwisewere carefully attuned to the three areas of survivorcentered programming addressed above. One service provider, a staffer at a LGBTQ youth center, described his group as serving clients "more on a spectrum basis", the most explicit connection to Halberstam's continuum we saw. Youth can drop in to the center for programming or socializing as needed. The more secure youth who "aren't really on their identity journey" on one side of the spectrum might not need to access the center for housing or food; rather, their concerns might be more emotional or psychological. Since the center operated with a more horizontal distribution of power, LGBTQ youth dropping in could easily "ask questions, both of our facilitators and mentors but also of their peers" (Interview by author, April 15, 2014).

For youth on the opposite ends of the spectrumthose most vulnerable to exploitation due to their particular circumstances-the LGBTQ youth shelter mobilized all their resources for youth to access if they so desired:

They are, they are in a situation where perhaps they came out and their parents or guardians or whomever they were living with is absolutely not supportive, and so they are just scrambling to find, "What's the next meal?" "Where am I living?" And all that housing and shelter and food question marks to keep living. Um, and so we'll absolutely help them and find them, you know, referrals to agencies in town that can provide that housing, we'll leverage our food pantry and get them, um, a meal and a supply of foods for the next several days. And then access to our clothing donation items to make sure they're, they're comfortable (Interview by author, April 15, 2014).

An LGBTQ anti-violence group also operated in a similar way for their most vulnerable clients, using a coalition of LGBTQ-friendly-or at least not hostileorganizations throughout the Kansas City metro to provide legal, medical, or social services that her own group was not equipped to facilitate. Survivors could leave or return to this organization, as moments of stability opened opportunities and moments of vulnerability closed them. Though not tailored specifically for LGBTQ populations, these groups in the Kansas City metro area were able to successfully mobilize these practices for the populations with which they worked, proving the necessity of these practices for marginalized persons. These interviews with LGBTQ organizations demonstrate that they are intentionally operating to "queer" their services and to apply the models of queer theory and activism within their service provision.

\subsection{Implications for Policy: Structural Factors to Prevent Trafficking}

Funding is a major issue for many of these social service providers. As survivor-centered approaches are less direct, they require more time, more staff, and more money. A director of a domestic violence shelter stated that "clients are staying longer and longer and longer" but "our economic situation is of course very difficult out there, more and more services that are cut so that they have less services" (Interview by author, November 14, 2013). The amount of money set aside for housing, therapy, job-training, and other important services does not reflect the number of survivors who need to access these programs. Survivors from marginalized positions become disproportionately affected by this reduction in services, increasing the violence they might experience and decreasing their ability to advocate for themselves (Aldridge, 2013).

Organizational coalition provides a temporary solution. Many organizations in the Kansas City metro area are connected at least informally, and a formal antitrafficking coalition links the medical, legal, and social service sectors. If a trafficking survivor enters through a sting operation or an arrest, they are immediately connected to case managers, lawyers, and medical professionals who can help them navigate the multiple channels presented to them.

The informal coalitions can be useful, but limited funding opportunities can also create tension between groups. As a service provider from an LGBTQ antiviolence group explains, "I think that sometimes with organizations they don't necessarily work together; it's more of a competition, like funding competition instead of providing holistic services for folks" (Interview by author, October 16, 2013). In the face of reduced services, coalitions must form in order for organizations to survive, but they also must battle the inadvertent competition that also comes from limited economic opportunities. Arguably, social inclusion is the ultimate goal of all social service providers working with vulnerable, exploited, or trafficked personswhether it be through traditional or queered approaches, all of these groups want their clients to move from victimization to survival. However, echoing Hedetoft's (2013) claim that "social inclusion encounters powerful opposition", the lack of equitable funding opportunities limits how these groups operate and what services they can provide (p. 1).

Funding issues also affect how social service pro- 
viders attack larger, structural inequalities. ${ }^{8}$ As stated earlier, one of the major factors in queered practices is the importance of combatting the structural inequalities that make exploitation or trafficking possible: racism, sexism, classism, homophobia, transphobia, and xenophobia. For many organizations, these factors directly contribute to who accesses their services and how their services are received. A service provider from a sexual violence advocacy organization said, "I think the biggest barrier we face as an agency is that stigma against sexual violence. And I think that stigma is informed by different things like racism or classism or just different economic barriers" (Interview by author, November 5,2013$)$. If the stigma against sexual violenceor LGBTQ persons or homelessness or traffickingpersists, then these cycles of violence will also persist.

However, structural inequalities are also deeply embedded in our society-we usually learn at a very young age what it means to be normal, socially legible, worthy of attention. If social service organizations want to tackle these issues, they must start the process when community members are not yet completely indoctrinated into these ideologies. Nearly all of the organizations we interviewed emphasized the importance of early intervention, beginning as soon as children enter institutions like day care or elementary school. A case manager from a state-level sexual violence advocacy organization discussed her organization's attempt to start the conversations amongst adolescents:

We have some groups that are focusing specifically on looking at issues like what does it mean to think of yourself as a man or a young man in society. What does masculinity mean? Things like that, we're trying to redefine the idea of masculinity be-

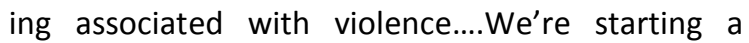
group with young girls too. A similar aspect we're trying to examine gender roles in society (Interview by author, October 21, 2013).

These groups require time, money, and staff presence for an extended amount of time, as structural inequalities cannot be eradicated in one year of programming.

\footnotetext{
${ }^{8}$ For LGBTQ organizations, the recent shift towards a singleissue platform-marriage equality-has resulted in changing funding priorities. Groups working outside of the coastal hubs of gay activism or working outside of the marriage equality narrative are left with few funding opportunities, unable to provide resources or access the same positions of social legitimacy. As Warner (1999) writes, "Too many activists see marriage only as a way of overcoming the stigma on identity and are willing to ignore-or even celebrate-the way it reinforces all of the other damaging hierarchies of shame around sex" (p. 115). As activists focused on same-sex marriage gain more attention-and the accompanying funding and support-groups that work with homeless, queer youth or incarcerated trans* people remain underfunded.
}

Consistency is necessary to attack these larger issues, but the social welfare climate-reductions in funding, limited resources for staffing, high turnover in organizations-cannot facilitate these practices. Increasing funding allows organizations to move beyond the survivor-centered approaches that help on the individual level but, unfortunately, cannot address the structural inequalities that keep the systems in place.

\section{Conclusions}

Anti-trafficking and violence organizations in the ASHTI project demonstrated again and again that in order to assist survivors, they need the resources and capabilities to implement a survivor-centered model of service provision. They also asserted that they need the cooperation with policy makers, educational leaders, and community organizations to systematically begin to address the social and economic inequalities that foster discrimination, exploitation, and vulnerability. Addressing the larger structural issues are the key to preventing trafficking before it begins and the key to keeping survivors from cyclical vulnerability. As the organizations needs are growing, the funding environment is becoming more and more constrained through cuts to education, housing, anti-violence programs, social services, jobs training, and youth programs. Spending money on the front end for prevention will not only be more cost-effective but, more importantly, can stop crimes and violence before they occur.

Ultimately, these social service providers are seeking to empower their survivors with the abilities to access a livable life, regardless of how they individually define it. As Butler (2004) writes, "Certain humans are recognized as less than human, and that form of qualified recognition does not lead to a viable life. Certain humans are not recognized as human at all, and that leads to yet another order of unlivable life" (p. 2). The vulnerable, exploited, or trafficked survivors who operate within the institutional frameworks of social service organizations must first be recognized as capable of living a viable life, as human. Following the lead of organizations in this study, developing survivor-centered approaches that are fluid and flexible, that challenge the idea of an "ideal victim", and that recognize the unique situations of LGBTQ persons, youth, and undocumented persons is key for the long-term battle to end trafficking and exploitation.

Our work with LGBTQ organizations also pointed to the importance of new frameworks for understanding agency. Queer theory can expand the concept of survivor possibility, resisting the "foreclos[ure] from possibility" that comes from the inability to recognize certain subjects as human (Butler, 2004, p. 31). By establishing a continuum-a more flexible approach, though certainly more convoluted and less predictable than linear models - the social service providers in the 
ASHTI project present a new way of operating within therapeutic or rehabilitative institutions. In honoring the agency present in their survivors, these service providers enact social change on a relational level: they return control to subjects once perceived to be incapable of exercising their own choices or autonomous desires. By disrupting linear therapeutic approaches that constrain how subjects comfortably navigate institutional frameworks, queer theory expands which subjects are allowed to exercise their agency and which survivor-driven actions are considered valuable and valid to create livable lives.

\section{Acknowledgements}

The authors would like to thank the Institute for Policy \& Social Research at the University of Kansas for their support of the ASHTI project, including funding, data management, and project facilitation. Funding for this project was provided by a Level II Strategic Initiative Grant from the University of Kansas and by the Department of Political Science at the University of Kansas. We would like to thank the entire ASHTI faculty working group for developing the theoretical foundations and research base for this project. In particular, we wish to acknowledge Dorothy Daley, Emily Rauscher, Megha Ramaswamy, Katie Cronin, Akiko Takeyama, Mariya Omelicheva, and Shannon O'Lear, Travis Weller, Steven Maynard-Moody, Xan Wedel, Kate Lorenz, and Larry Hoyle. Additionally, we must thank graduate research assistants Danny Alvord and Andrew Zarda for their work conducting interviews with service providers in the Kansas City metro area, and undergraduate research assistants Allison Williams, Jylessa Hampton, and Nick Ball for their work on the transcriptions. Finally, we want to thank the service providers whose interviews provided such rich insights into the cycles of vulnerability, exploitation, and trafficking that exist in Kansas City and neighboring communities.

\section{Conflict of Interests}

The authors declare no conflict of interests.

\section{References}

Ahmed, S. (2000). Strange encounters: Embodied others in post-coloniality. London: Routledge.

Aldridge, J. (2013). Identifying the barriers to women's agency in domestic violence: The tensions between women's personal experience and systemic responses. Social Inclusion, 1(1), 3-12.

Annitto, M. (2011). Consent, coercion, and compassion: Emerging legal responses to the commercial sexual exploitation of minors. Yale Law \& Policy Review, 30(1), 1-70.
Anzaldua, G. (1987). Borderlands/la frontera: The new mestiza. San Francisco: Aunt Lute Books.

Bales, K., \& Trodd Z. (Eds.). (2008). To plead our own cause: Personal stories by today's Slaves. Ithaca, NY: Cornell University Press.

Brennan, D. (2005). Methodological challenges in research on human trafficking: Tales from the field. International Migration, 43(1-2), 45-61.

Britton, H., \& Dean, L. (2014). Policy responses to human trafficking in Southern Africa: Domesticating international norms. Human Right Review, 15, 305-328.

Butler, J. (2004). Undoing gender. New York: Routledge.

Center for Disease Control. (2013). The socialecological model: A framework for prevention. Retrieved from http://www.cdc.gov/violencepreven tion/overview/social-ecologicalmodel.html

Clawson, H. J., \& Dutch N. (2008). Case management and the victim of human trafficking: A critical service for client success. U.S. Department of Health and Human Services. Retrieved from http://aspe.hhs.gov/hsp/ 07/humantrafficking/casemgmt/ib.pdf

Crenshaw, K. (1989). Demarginalizing the intersections of race and sex: A black feminist critique of antidiscrimination doctrine, feminist theory, and antiracist politics. The University of Chicago Legal Forum, 139, 139-167.

Farrell, A., McDevitt, J., \& Fahy S. (2010). Where are all the victims? Understanding the determinants of official identification of human trafficking incidents. Criminology \& Public Policy, 9, 201-233.

Farrell, A., McDevitt, J., Perry, N., Fahy, S., Chamberlain, K., Adams, W., Owens, C., Dank, M., Shively, M., Kling, R., \& Wheeler, K. (2009). Review of existing estimates of victims of human trafficking in the United States and recommendations for improving research and measurement of human trafficking. Washington, DC: Humanity United.

Farrell, A., McDevitt, J., Pfeffer, R., Fahy, S., Owens, C., Dank, M. \& Adams, W. (2012). Identifying challenges to improve the investigation and prosecution of state and local human trafficking cases. Washington, DC: Northeastern University and Urban Institute.

Ferguson-Colvin, K. M., \& Maccio, E. M. (2012). Toolkit for practitioners/researchers working with Lesbian, Gay, Bisexual, Transgender, and Queer/Questioning (LGBTQ) Runaway and Homeless Youth (RHY). New York, NY: National Resource Center for Permanency and Family Connections Silberman School of School of Social Work. Retrieved from http://www.hunter.c uny.edu/socwork/nrcfcpp/info_services/download/L GBTQ\%20HRY\%20Toolkit\%20September\%202012.pdf

Goodey, J. (2008). Human trafficking: Sketchy data and policy responses. Criminology Criminal Justice, 8(4), 421-442.

Gordon, D. M., \& Hunter B. A. (2013). Invisible no more: Creating opportunities for youth who are homeless. New Haven, CT: The Consultation Center Yale Uni- 
versity School of Medicine. Retrieved from http://www.pschousing.org/files/InvisibleNoMoreR eport.pdf

Gozdziak, E., \& Collett. E. A. (2005). Research on human trafficking in North America: A review of literature. International Migration, 43(1-2), 99-128.

Halberstam, J. (2005). In a queer time \& place: Transgender bodies, subcultural lives. New York: New York University Press.

Hedetoft, U. R. (2013). Social inclusion, inaugural editorial. Social Inclusion, 1(1), 1-2.

Hoyle, C., Bosworth, M., \& Dempsey, M. (2011). Labelling the victims of sex trafficking: Exploring the borderland between rhetoric and reality. Social and Legal Studies, 20(3), 313-329.

Icduygu, A., \& Toktas, S. (2002). How do smuggling and trafficking operate via irregular border crossings in the Middle East? International Migration, 40(6), 2552.

Kaneti, M. (2011). Project trafficking: Global unity in addressing a universal challenge? Human Rights Review, 12, 345-361.

Konstantopoulous, W. M., Ahn, R., Alpert, E. J., Cafferty, E., McGahan, A., Williams, T. P., Castor, J. P., Wolferstan, N., Purcell, G., \& Burke T. F. (2013). An international comparative public health analysis of sex trafficking of women and girls in eight cities: Achieving a more effective health sector response. Journal of Urban Health, 90(6), 1194-1204.

Laczko, F., \& Gramegna, M. (2003). Developing better indicators of human trafficking. Journal of World Affairs, 10(1), 179-194.

Lindstrom, N. (2006). Transnational responses to human trafficking in the Balkans (International Affairs Working Paper, 2006-09). Retrieved from http:// milanoschool.org/wp-content/uploads/2013/04/ Lindstrom_2006-09.pdf

Lobasz, J. K. (2009). Beyond border security: Feminist approaches to human trafficking. Security Studies, 18, 319-344.

Long, J. G. (2012). Enhancing prosecutions of human trafficking and related violence against sexually exploited women. Strategies: The Prosecutors' Newsletter on Violence Against Women, 6, 1-10. Retrieved from http://www.aequitasresource.org/ Enhancing-Prosecutions-of-Human-Trafficking.pdf

Munro, V. (2008). Of rights and rhetoric: Discourses of degradation and exploitation in the context of sex trafficking. Journal of Law and Society, 35(2), 240264.

National Research Council of the National Academies, $\&$ Institute of Medicine. (2013). Confronting commercial sexual exploitation and sex trafficking of minors in the United States. Washington, DC: Na- tional Research Council of the National Academies, \& Institute of Medicine.

O'Brien, E. (2012). Ideal victims in trafficking awareness campaigns. In K. Carrington, M. Ball, E. O'Brien, \& J. Tauri (Eds.), Crime, justice and social democracy: International perspectives. Palgrave Macmillan: Basingstoke

Oxman-Martinez, J., Hanley, J., \& Gomez, F. (2005). Canadian policy on human trafficking: A four-year analysis. International Migration, 43(4), 7-29.

Primrose, S. (2011). Killing the messenger: The intersection between sex trafficking, planned parenthood, and the marginalization of youth victims. University of Florida Journal of Law and Public Policy, 22, 299333.

Smith, H. M. (2011). Sex trafficking: Trends, challenges, and the limitations of international law. Human Rights Review, 12, 271-286

Srikantiah, J. (2007). Perfect victims and real survivors: The iconic victim in domestic human trafficking law. Boston University Law Review, 87(156), 158-211.

Todres, J. (2011). Moving upstream: The merits of a public health law approach to human trafficking. North Carolina Law Review, 89, 447-506.

Todres, J. (2012). Assessing public health strategies for advancing child protection: Human trafficking as a case study. Journal of Law and Policy, 21, 93-112.

Tyldum, G., \& Brunovskis, A. (2005). Describing the unobserved: Methodological challenges in empirical studies on human trafficking. International Migration, 43(1-2), 17-34.

United States Department of Justice. (2006). Assessment of U.S. Government efforts to combat trafficking in persons in fiscal year 2005. Washington, DC: United States Department of Justice.

Warner, M. (1999). The trouble with normal: Sex, politics, and the ethics of queer life. New York: Free Press.

Weir, A. (2008). Global feminism and transformative identity politics. Hypatia, 23(4), 110-133.

Weitzer, R. (2005). Flawed theory and method in studies of prostitution. Violence against Women, 11(7), 934-949.

Zhang, S. (2012). Looking for a hidden population: Trafficking of migrant laborers in San Diego County (Final report to the US Department of Justice, Doc. no.: 240223). San Diego, CA: San Diego State University. Retrieved from https://www.ncjrs.gov/ pdffiles1/nij/grants/240223.pdf

Zimmerman, C., Hossain, M., \& Watts, C. (2011). Human trafficking and health: A conceptual model to inform policy, intervention and research. Social Science \& Medicine, 73, 327-335. 


\section{About the Authors}

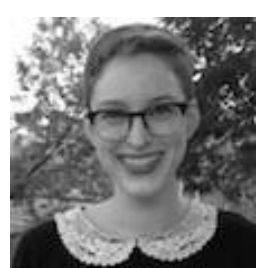

\section{Corinne Schwarz}

Corinne Schwarz is a PhD student in the Women, Gender, and Sexuality Studies Department at the University of Kansas. Her research looks at the intersections of anti-human trafficking interventions and health services delivery in rural and underserved communities. She is also interested in policy efforts to support the relationship between anti-trafficking advocates and public health officials.

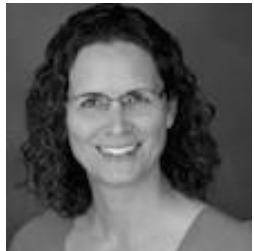

\section{Dr. Hannah E. Britton}

Hannah E. Britton is an Associate Professor of Political Science and Women, Gender, and Sexuality Studies at the University of Kansas. She is the Director of the Center for the Study of Inequality at the Institute of Policy \& Social Research at the University of Kansas. Her research focuses on gender and African politics, community-based strategies to end gender-based violence, and public health approaches to prevent human trafficking and exploitation. 